EXTENDED REPORT

\title{
Leflunomide inhibits transendothelial migration of peripheral blood mononuclear cells
}

\author{
J Grisar, M Aringer, M D Köller, G H Stummvoll, D Eselböck, B Zwölfer, C W Steiner, B Zierhut, \\ L Wagner, P Pietschmann, J S Smolen
}

Ann Rheum Dis 2004;63:1632-1637. doi: 10.1136/ard.2003.018440

See end of article for authors' affiliations

.....................

Correspondence to: Dr J Grisar, Division of Rheumatology,

Department of Internal Medicine III, Medical University of Vienna, Waehringer Guertel 18-20, A-1090 Vienna, Austria; johannes.grisar@ medun-wien.ac.at

Accepted

22 February 2004
Objectives: To test whether the active metabolite of leflunomide (LEF-M), in addition to blocking the proliferation of activated lymphocytes by inhibiting dihydro-orotate dehydrogenase (DHODH), influences the transendothelial migration (TEM) of peripheral blood mononuclear cells (PBMC).

Methods: In an in vitro model of PBMC transmigration through an endothelial cell (EC) barrier, PBMC were re-collected in three groups: cells not adherent to the EC, cells bound to, and cells which had migrated through, the EC layer. Experiments in which cells were pretreated with LEF-M (in the absence or in the presence of uridine) were compared with parallel experiments in the presence of medium alone.

Results: Preincubation of EC with LEF-M led to a 36 (SEM 16)\% reduction in PBMC TEM ( $<<0.05)$. Likewise, preincubation of PBMC induced a reduction in their TEM of $39(9) \%(p<0.005)$. Incubation of both PBMC and EC with LEF-M had an additive effect (mean reduction of $48(6) \%, p<0.005)$. Incubation of PBMC with LEF-M also decreased monocytic CD44 expression $(p<0.005)$ and PBMC-hyaluronan binding $(p<0.05)$. Incubation of cells with LEF-M and uridine in addition to LEF-M reversed the inhibition of migration, suggesting that the observed effects were due to $\mathrm{DHODH}$ inhibition. Fluorocytometric analysis of PBMC subsets within the migrated population showed a decrease of monocytes, but not of $B$ or T cells, after LEF-M treatment.

Conclusions: LEF-M reduces monocytic adhesion molecule expression and TEM and may thus interfere with monocyte and EC activities in RA. Thus, the clinical effects of leflunomide may, at least in part, be due to blocking cell traffic into the inflamed synovia.
A lthough rheumatoid arthritis (RA) is a systemic disease, most of its pathology of takes place within the joints. ${ }^{12}$ One of the hallmarks of RA is the accumulation of inflammatory cells and subsequent hypercellularity in the synovial membrane, and the replenishment of these cells is an important process in the continuing inflammation of RA. ${ }^{1-3}$ To a great extent such recruitment to inflammatory sites is mediated by endothelial events ${ }^{1}$ and, in fact, blocking the transendothelial migration (TEM) by monoclonal antibodies to adhesion molecules constitutes an interesting therapeutic approach in RA. ${ }^{4}$ Both endothelial cells (EC) and leucocytes participate in the process of migration, which can be mimicked, at least in part, in vitro. ${ }^{5}$

Leflunomide is a new disease modifying antirheumatic drug (DMARD). ${ }^{6}{ }^{7}$ Its active metabolite, A771 726, blocks the enzyme dihydro-orotate dehydrogenase (DHODH), ${ }^{8}$ thereby inhibiting the de novo synthesis of pyrimidines. Because pyrimidine synthesis is of critical importance to allow cell division, leflunomide appears to target proliferating cells such as activated T cells. ${ }^{9}$ Leflunomide also inhibits nuclear factor $\kappa \mathrm{B}(\mathrm{NF}-\kappa \mathrm{B})$, a transcription factor activated by proinflammatory cytokines. ${ }^{10}$

Recent studies of synovial biopsies and magnetic resonance imaging in patients with RA undergoing DMARD treatment have shown that leflunomide, when compared with baseline and even with methotrexate treatment, significantly reduced synovial cellularity. ${ }^{11}{ }^{12}$ Although this finding could be explained by the effect of leflunomide on proliferating cells or by effects on cytokine production or other downstream events, we wondered if leflunomide might also affect peripheral blood mononuclear cell (PBMC) migration.

In this study we show that leflunomide significantly reduces TEM and that the mode of action of this DMARD is due to effects on both EC and PBMC.

\section{MATERIALS AND METHODS \\ Cell cultures}

EC were isolated from human umbilical cord veins by collagenase digestion, as previously described, ${ }^{13}$ and then cultured in MCDB-M 104 medium (Gibco, Paisley, United Kingdom) supplemented with $20 \%$ fetal calf serum, $24 \mu \mathrm{g} / \mathrm{ml}$ EC growth supplement (TC Laevosan, Vienna, Austria), $50 \mathrm{U} / \mathrm{ml}$ heparin, L-glutamine $(2 \mathrm{mM})$, penicillin (100 U/ $\mathrm{ml})$, and streptomycin $(100 \mu \mathrm{g} / \mathrm{ml}$; all from Gibco). For all experiments EC in the third to fifth passage were used. To form a confluent monolayer on the collagen gels (see below), $5 \times 10^{5}$ EC per well were incubated for 24 hours.

PBMC were obtained from heparinised venous blood of healthy volunteers and of patients with RA fulfilling the 1987 American College of Rheumatology criteria, by density gradient centrifugation (Ficoll-Paque plus; Amersham Pharmacia Biotech AB, Uppsala, Sweden). For additional experiments, highly purified (to $>95 \%$ ) monocyte and/or $\mathrm{T}$ cell populations were prepared from the PBMC using negative selection by magnetic cell sorting (monocyte isolation kit and pan T cell isolation kit, MACS; Miltenyi, Bergisch Gladbach, Germany). PBMC or T cells or monocytes were then cultured for 24 hours in $33 \mathrm{~mm}$ macrowell plates (Nunc A/S, Roskilde, Denmark).

In some experiments, PBMC, T cells, monocytes, or EC were incubated with the active metabolite of leflunomide,

\footnotetext{
Abbreviations: BND, bound; Dex, dexamethasone; DHODH, dihydroorotate dehydrogenase; DMARD, disease modifying antirheumatic drug; EC, endothelial cell(s); LEF-M, metabolite of leflunomide, A771 726; MCP, monocyte chemotactic protein; MFI, mean fluorescence intensity; MIG, migrated; MIP-1 $\alpha$, macrophage inhibitory protein-1 $\alpha$; MTX, methotrexate; NAD, non-adherent; NF- $\kappa B$, nuclear factor $\kappa B$; PBMC, peripheral blood mononuclear cell(s); PBS, phosphate buffered saline; RA, rheumatoid arthritis; TEM, transendothelial migration
} 


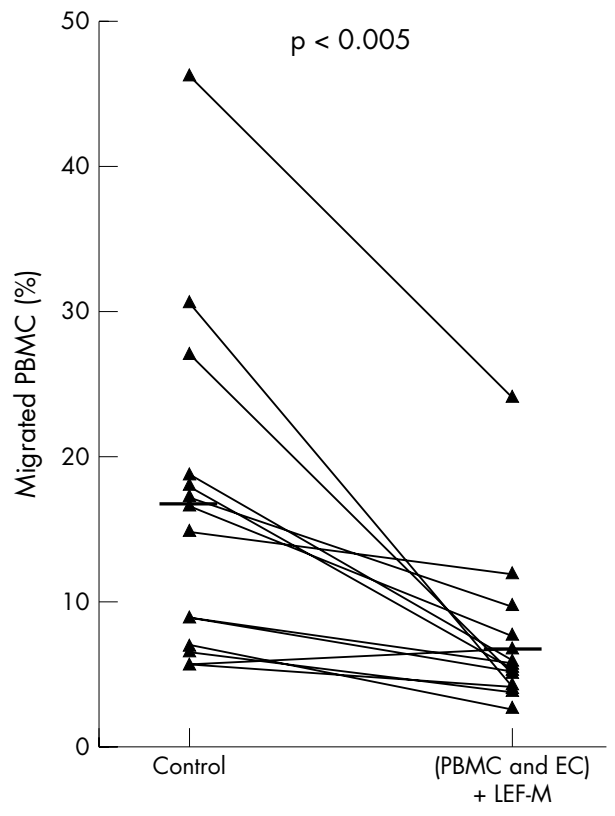

Figure 1 LEF-M decreases the transendothelial migration of PBMC both in healthy subjects and patients with RA. In 14 experiments, EC and PBMC of healthy volunteers were preincubated with $100 \mu \mathrm{M}$ LEF-M for 24 hours. A significant decrease in the percentage of migrated PBMC was found as compared with control experiments $(17(3) \% \vee 7(1) \%$, $\mathrm{p}<0.005$ )

A771 726 (LEF-M, courtesy of Aventis, Strasbourg, France), at different concentrations. Unless mentioned otherwise, $100 \mu \mathrm{M}$ LEF-M was used. Among tested concentrations in the range of therapeutic serum levels, this concentration was found to give maximal effects without toxicity on PBMC (see below).

For comparative purposes, PBMC and EC were preincubated with methotrexate (MTX; Alexis Corporation, Lausen, Switzerland) or dexamethasone (Dex; Sigma-Aldrich, St Louis, MI, USA) in concentrations from 0.1 to $10 \mu \mathrm{mol} / 1^{14}$ for MTX and 1-100 nmol/ $/ \mathrm{l}^{15}$ for Dex, respectively.

\section{Transendothelial migration and adhesion capacity}

Cell migration was studied on hydrated bovine collagen gels in $16 \mathrm{~mm}$ macrowell tissue culture plates (Nunc A/S), as previously described. ${ }^{513}$ To investigate the degree of TEM, PBMC $\left(3 \times 10^{6}\right)$ were layered on top of collagen gels with EC and incubated at $37^{\circ} \mathrm{C}$ for 1 hour. ${ }^{13}$ We have previously shown that the EC layer is a decisive element in this assay and clearly enhances transmigration. ${ }^{13}$ Cells that were nonadherent (NAD) to EC were harvested by washing twice with culture medium. Cells bound (BND) to the EC surface were removed by washing twice with warm $\left(37^{\circ} \mathrm{C}\right)$ Puck's EDTA, twice with warm $\left(37^{\circ} \mathrm{C}\right)$ EGTA $\left(0.5 \times 10^{-3} \mathrm{M}\right.$ EGTA in phosphate buffered saline (PBS)), and once with cold $\left(4^{\circ} \mathrm{C}\right)$ Puck's EDTA. ${ }^{5}$ Finally, for the recovery of those cells that had migrated (MIG) into the collagen gels, $0.7 \mathrm{ml}$ of a collagenase solution (0.1\% collagenase, Sigma) was added to each well. Then the collagen gels were gently minced with a pipette and incubated for 60 minutes at $37^{\circ} \mathrm{C}$. After incubation, MIG PBMC were recovered by washing the wells twice with PBS. Each population (NAD, BND, and MIG) was washed, resuspended in culture medium, and subjected to cell counting and analyses of cell surface marker expression by flow cytometry (see below). The percentage decrease of MIG PBMC was calculated by the formula:

$(1-($ MIG LEF - M/MIG control $)) \times 100$
Analyses of the influence of leflunomide on cell migration required PBMC preincubated with LEF-M and untreated EC, untreated PBMC, and pretreated EC, as well as coculture of both populations, either pretreated or untreated. In addition, we performed experiments, pretreating PBMC and EC with both LEF-M and uridine (at a concentration of $100 \mu \mathrm{mol} / \mathrm{l}$ ) to test if uridine could rescue PBMC from the observed effects of LEF-M on TEM, which would suggest dependence on the enzyme DHODH. ${ }^{16}$ Addition of LEF-M to PBMC or EC immediately before testing for migration induced no significant change in cell migration (data not shown). Therefore, to imitate in vivo conditions, in those experiments where PBMC and/or EC were preincubated with LEF-M before the migration assay, cells were resuspended in medium containing LEF-M after washing them with PBS and before incubation on the monolayer.

To further test if LEF-M influenced the adhesion to EC, the following experiments were performed: EC with or without LEF-M were incubated overnight on gelatin covered $16 \mathrm{~mm}$ macrowell tissue culture plates $\left(5 \times 10^{5}\right.$ cells/well $)$ without the presence of a subendothelial collagen gel. Subsequently PBMC, untreated or LEF-M pretreated, were added to the EC covered wells at $3 \times 10^{6} \mathrm{PBMC} /$ well and incubated for 1 hour. Non-adherent cells were recovered by gentle washing, adherent cells by gentle mincing and washing; cells were then counted and analysed by flow cytometry.

To test for potential toxicity of LEF-M we analysed cell mortality by trypan blue exclusion after re-collecting cells from the monolayer. In addition, we incubated PBMC for 24 hours with and without $100 \mu \mathrm{M}$ LEF-M and used a Coulter counter to determine cell loss (Coulter Electronics Ltd, Luton, UK).

\section{Flow cytometry of PBMC}

To characterise potential preferential adhesion or migration of PBMC subpopulations, PBMC and PBMC subsets recollected in the respective cell populations were analysed by flow cytometry. Cells were stained with fluorescein isothiocyanate or phycoerythrin conjugated monoclonal antibodies against CD3 and CD14 (Becton \& Dickinson, Sparks, MD, USA), and in some experiments also against CD4, CD8 (Becton \& Dickinson), and CD19 (Immunotech, Westbrook, ME, USA), according to standard procedures. ${ }^{13}$ Analysis was performed on a Becton \& Dickinson "FACScan" flow cytometer. Results are expressed as the percentage of positive

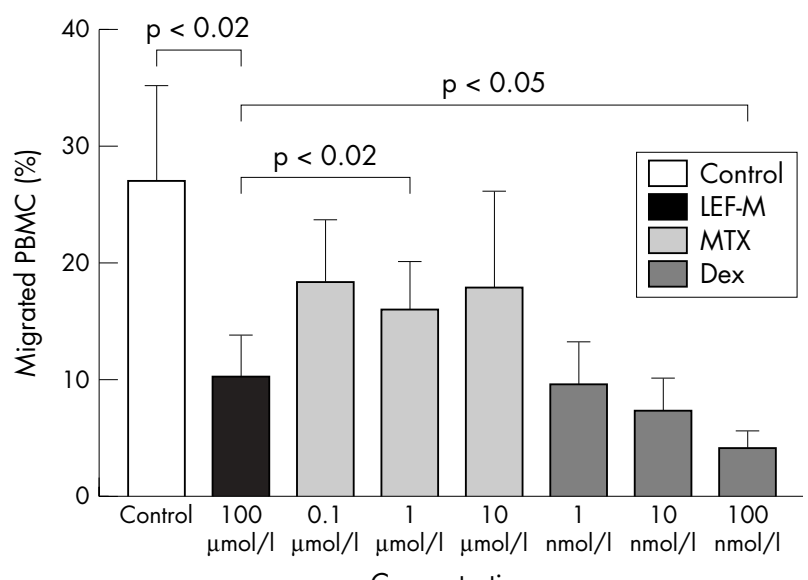

Figure 2 MTX does not significantly affect TEM (MTX at all doses $v$ controls $p=N S)$, contrasting with the effect of LEF-M ( $p<0.02 v$ control). Dex was highly effective in TEM inhibition $(p<0.02$ at doses of 1 and $10 \mathrm{nmol} / \mathrm{l}$ Dex $v$ controls, $\mathrm{p}<0.05$ at a dose of $100 \mathrm{nmol} / \mathrm{I}$ Dex $v$ control). 


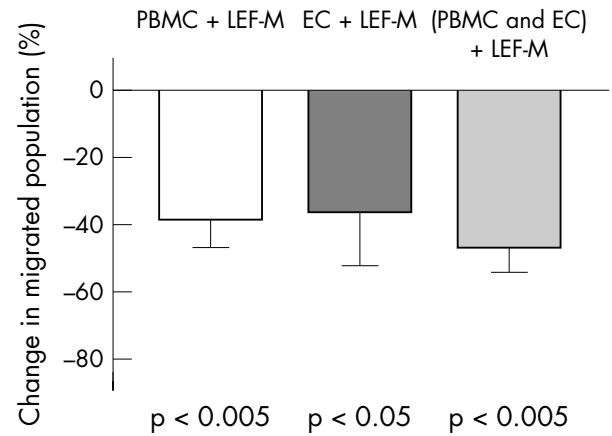

Figure 3 Treatment of either PBMC or EC with LEF-M decreases the transendothelial migration of PBMC. Preincubation for 24 hours of PBMC or EC or PBMC and EC with $100 \mu \mathrm{M}$ LEF-M induced a significant decrease in the percentage of migrated cells (PBMC $39(9) \%$ v $48(6) \%$, $p<0.005$; EC: $36(16) \%$ v $48(6) \%, p<0.05)$.

cells, or when indicated, as the mean fluorescence intensity (MFI).

\section{Analysis of the influence of LEF-M on PBMC and EC adhesion molecule expression and hyaluronan binding}

PBMC or EC were incubated for 24 hours with LEF-M at a concentration of $100 \mu \mathrm{mol} / \mathrm{l}$. Expression of the following cell surface molecules, which are known to have important roles in TEM, was measured as described above, using isotype matched appropriate non-specific antibodies (Becton \& Dickinson) as negative controls: CD2, CD25, CD44 (Becton \& Dickinson), CD1 la, CD29, CD49d (Immunotech), CD18, CD69 (Serotec, Oxfordshire, United Kingdom), and CD62L (Pharmingen, San Diego, CA, USA) were analysed on PBMC. Anti-CD29 and anti-CD44 and antibodies to CD50 (ICAM-3), CD54 (ICAM-1), CD62E (E-selectin), CD62P (P-selectin), CD102 (ICAM-2), CD106 (from Serotec), and HLA-DR (Beckmann Coulter, Fullerton, CA, USA) were used to analyse EC.

To test the influence of LEF-M on the function of CD44, we determined the binding of fluorescein conjugated hyaluronic acid (Molecular Probes Inc, Eugene, OR, USA) to untreated or LEF-M pretreated PBMC by fluorescence activated cell sorter analysis.

Results are expressed as the MFI.

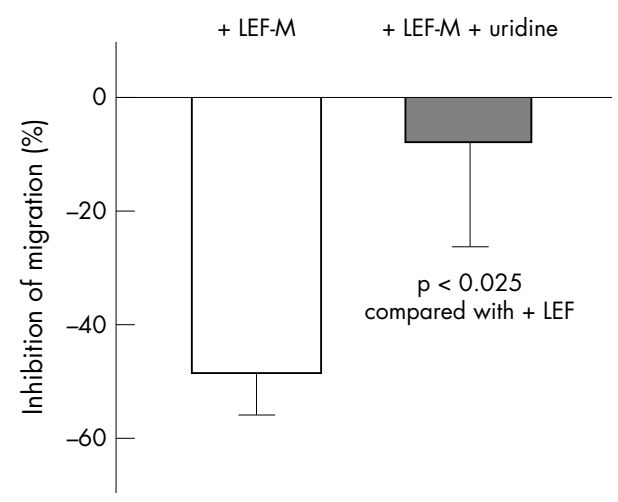

Figure 4 The effect of transendothelial migration is reversed by uridine. When PBMC and EC were incubated for 24 hours with both LEF-M and uridine, transendothelial migration significantly increased as compared with parallel control experiments where cells were incubated solely with LEF-M (decreased by 48 (8)\% with LEF-M v 8 (1)8\% with LEF-M and uridine, $p<0.025)$. However, no significant decrease between untreated PBMC and PBMC preincubated with LEF-M and uridine was seen.

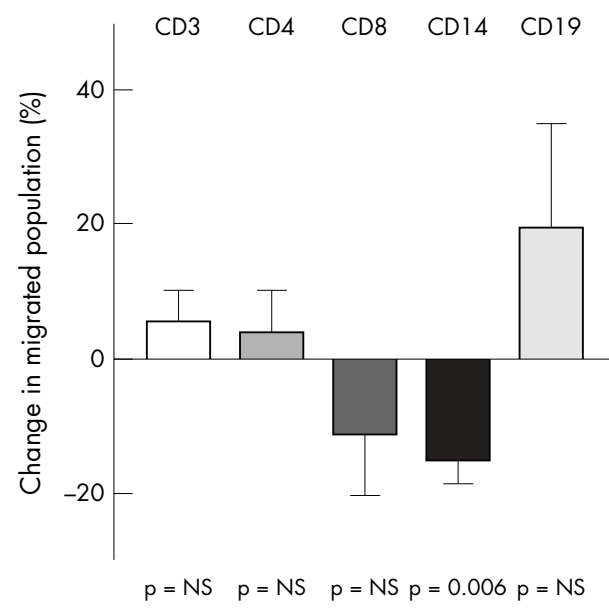

Figure 5 LEF-M decreases the migration of CD14 positive cells. In the presence of LEF-M the percentage of CD14 positive cells (that is, monocytes) in the migrated population significantly decreased (by 15 $(4) \%, p=0.006)$, whereas T and B lymphocytes showed no altered cell counts in the migrated fraction.

\section{Chemotaxis}

To determine, if LEF-M would also influence basal chemotaxis, chemotaxis assays were performed: $2 \times 10^{4}$ PBMC or $1 \times 10^{4}$ negatively selected monocytes from healthy donors, untreated or pretreated with $100 \mu \mathrm{M}$ LEF-M for 24 hours, washed and resuspended in RPMI 1640 containing 1\% bovine serum albumin, were added to the top of a chemotaxis chamber (Neuro Probe Inc, Gaithersburg, MD, USA). $30 \mu \mathrm{l}$ of 10 -fold serially diluted $(0.1-1000 \mathrm{ng} / \mathrm{ml})$ monocyte chemotactic protein-3 (MCP-3; R \& D Systems, Wiesbaden, Germany) or, for PBMC only, MCP-1 plus macrophage inhibitory protein-l $\alpha$ (MIP- $1 \alpha$; both Sigma-Aldrich) was placed in the bottom wells of the chamber, separated from the cell suspension by a polycarbonate filter ( $5 \mu \mathrm{m}$ pore size). The chamber was incubated at $37^{\circ} \mathrm{C}$ and $5 \% \quad \mathrm{CO}_{2}$ for 90 minutes. Cells which migrated were then counted in the bottom well in duplicate samples.

\section{Statistical analyses}

Where applicable, data are presented as mean (SEM). A paired Student's $t$ test or, when distributions were not normal, a Kruskal-Wallis test was used for the statistical analyses.

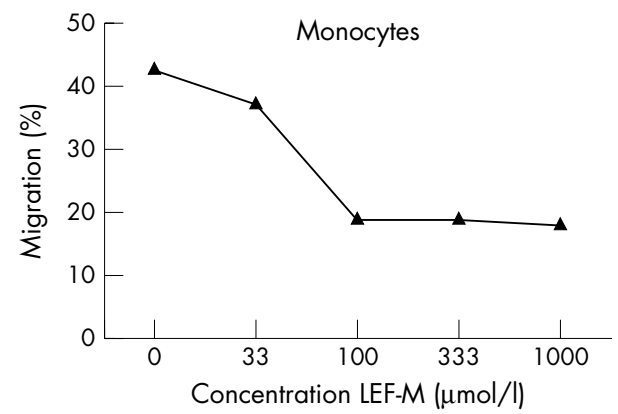

Figure 6 Dose-response of LEF-M. Dose-response experiments with highly purified monocytes indicated that a dose of $100 \mu \mathrm{mol} / \mathrm{I}$ LEF-M clearly inhibits TEM. This concentration was used for all other experiments. 
Table 1 Surface adhesion molecules on PBMC incubated with $100 \mu \mathrm{M}$ LEF-M for 24 hours $v$ control experiments

\begin{tabular}{|c|c|c|c|c|c|c|}
\hline \multirow[b]{2}{*}{ Marker } & \multirow[b]{2}{*}{ Function } & \multicolumn{2}{|l|}{ Control } & \multicolumn{2}{|l|}{+ LEF-M } & \multirow{2}{*}{$\begin{array}{l}\text { p Value } \\
\text { (paired } \\
t \text { test, MFI) }\end{array}$} \\
\hline & & MFI & $\{\%$ pos $\}$ & MFI & $\{\%$ pos $\}$ & \\
\hline CD2 & Adhesion, $\mathrm{T}$ cell activation & $53.7(3.0)$ & $\{71(2)\}$ & $55.5(3.0)$ & $\{72(2)\}$ & NS \\
\hline CDIla & Adhesion & $170.9(16.2)$ & $\{97(0)\}$ & $161.8(13.1)$ & $\{95(1)\}$ & NS \\
\hline CD18 & Adhesion & $56.0(6.0)$ & $\{62(5)\}$ & $58.4(4.9)$ & $\{57(6)\}$ & NS \\
\hline CD25 & Cell proliferation and differentiation & $9.4(1.3)$ & $\{4(1)\}$ & $9.9(1.3)$ & $\{3(0)\}$ & NS \\
\hline CD29 & Adhesion and signal transduction & $67.7(4.4)$ & $\{65(3)\}$ & $61.1(2.3)$ & $\{58(5)\}$ & \\
\hline CD44 & $\begin{array}{l}\text { Extra- and intercellular adhesion, leucocyte homing, } \mathrm{T} \text { cell } \\
\text { costimulation }\end{array}$ & $351.0(15.1)$ & $\{99(0)\}$ & $324.9(17.5)$ & $\{99(0)\}$ & $<0.05$ \\
\hline CD49d & Adhesion & $37.3(5.0)$ & $\{53(5)\}$ & $33.0(1.4)$ & $\{40(6)\}$ & NS \\
\hline CD62L & Adhesion, leucocyłe homing, rolling, and extravasation & $98.2(11.5)$ & $\{98(12)\}$ & $93.3(7.8)$ & $\{93(8)\}$ & NS \\
\hline CD69 & Costimulation & $14.0(0.7)$ & $\{9(1)\}$ & $14.6(0.8)$ & $\{7(1)\}$ & NS \\
\hline
\end{tabular}

\section{RESULTS \\ Leflunomide reduces transendothelial migration of PBMC}

To test if leflunomide affected the TEM of PBMC, both PBMC and EC were preincubated for 24 hours with $100 \mu \mathrm{M}$ LEF-M (established as the optimal dose in dose-response analyses) before the migration assay. In healthy volunteers, a significant decrease in the percentage of migrated PBMC from a mean (SEM) of 17 (3)\% (range 6-47\%) without LEF$M$ to a mean of 7 (1)\% (range 3-26\%) with LEF-M pretreatment $(\mathrm{p}<0.005)$ was seen (fig 1$)$. Incubation of PBMC of patients with RA with LEF-M likewise led to a significant reduction in TEM (16 (2)\% without LEF-M $v 12$ (2)\% with LEF-M of migrated PBMC, ranges: $7-30 \%$ without $v 5-28 \%$ with LEF-M, $\mathrm{p}<0.005$, paired $t$ test).

As expected, the proportion of the NAD PBMC increased accordingly (57 (5)\% without $v 69$ (3)\% with LEF-M, $\mathrm{p}<0.01)$; the BND population was not significantly influenced.

The observed decrease in spontaneous TEM was not due to toxic effects of LEF-M, because no significant difference in the percentage of trypan blue positive cells was seen (9 (3)\% without $v 10(2) \%$ with LEF-M, p = NS). Also, when counting pretreated and untreated PBMC after 24 hours' incubation no significant difference between the two groups was detected (PBMC incubated in medium: 100\%, PBMC incubated with LEF-M: 107\%, mean of six experiments).

\section{MTX does not inhibit TEM}

Preincubation of PBMC and EC with MTX showed that this DMARD did not significantly reduce TEM (fig 2) compared with control, suggesting that the pronounced inhibition in
TEM is not common to all DMARDs. In contrast, Dex was highly effective in inhibiting TEM (fig 2).

\section{PBMC and $E C$ are affected by leflunomide}

To elucidate if LEF-M interfered with PBMC, EC, or both, a series of experiments preincubating the populations separately was performed. When PBMC, but not EC, were preincubated with LEF-M for 24 hours, the frequency of migrated cells decreased by a mean (SEM) of 39 (9)\% $(\mathrm{p}<0.005)$ compared with untreated PBMC (fig 3). Likewise, when only EC were preincubated with LEF-M, migration also tended to decrease by $36(16) \%(\mathrm{p}<0.05)$ compared with migration on untreated EC (fig 3). Thus, LEF-M inhibited cell migration through events both in PBMC and EC. However, each of these effects was somewhat less pronounced than the simultaneous incubation of both cell populations with LEF-M (mean percentage inhibition of migration $48(6) \%, \mathrm{p}<0.005)$, suggesting additive effects.

\section{Effects of leflunomide are inhibited by addition of uridine}

Next, we tested if the impairment of TEM could be prevented by incubation in the presence of uridine as an external pyrimidine source. When EC and PBMC were incubated with both LEF-M and uridine, the decrease in TEM, compared with simultaneous control experiments with LEF-M only, was almost completely inhibited (fig 4).

\section{Effects of leflunomide on monocyte and lymphocyte migration and adhesion}

We then analysed which PBMC subsets were preferentially influenced within their migration behaviour by LEF-M. After

Table 2 Surface adhesion molecule expression on EC incubated with $100 \mu$ M LEF-M for 24 hours $v$ control experiments

\begin{tabular}{|c|c|c|c|c|c|c|}
\hline \multirow[b]{2}{*}{ Marker } & \multirow[b]{2}{*}{ Function } & \multicolumn{2}{|l|}{ Control } & \multicolumn{2}{|l|}{ + LEF-M } & \multirow{2}{*}{$\begin{array}{l}\text { p Value } \\
\text { (paired } \\
t \text { test, MFI) }\end{array}$} \\
\hline & & MFI & $\{\%$ pos $\}$ & MFI & $\{\%$ pos $\}$ & \\
\hline CD29 & Adhesion and signal transduction & $102.7(14.3)$ & $\{99(0)\}$ & $86.6(10.7)$ & $\{99(0)\}$ & NS \\
\hline CD34 & Adhesion & $2.2(0.3)$ & $\{2(1)\}$ & $2.2(0.3)$ & $\{3(1)\}$ & NS \\
\hline CD44 & Extra- and intercellular adhesion, leucocyte homing, $T$ cell costimulation & $22.0(2.9)$ & $\{71(6)\}$ & $18.5(2.2)$ & $\{66(8)\}$ & NS \\
\hline CD50 & Adhesion & $3.9(0.5)$ & $\{10(1)\}$ & $3.5(0.4)$ & $\{8(1)\}$ & NS \\
\hline CD54 & Adhesion, leucocyte TEM & $9.0(1.9)$ & $\{43(7)\}$ & $9.9(1.9)$ & $\{43(5)\}$ & NS \\
\hline CD62E & Adhesion, leucocyte rolling and extravasation & $4.6(0.5)$ & $\{18(2)\}$ & $4.6(0.4)$ & $\{18(2)\}$ & NS \\
\hline CD62P & Intercellular adhesion, leucocyte rolling, and extravasation & $2.9(0.3)$ & $\{5(1)\}$ & $2.7(0.3)$ & $\{4(1)\}$ & NS \\
\hline CD102 & Adhesion, $T$ cell costimulation & $60.7(17.0)$ & $\{98(0)\}$ & $44.2(12.3)$ & $\{96(1)\}$ & $<0.05$ \\
\hline CD106 & Lymphocyte adhesion & $32.4(10.4)$ & $\{2(0)\}$ & $35.1(15.8)$ & $\{4(3)\}$ & NS \\
\hline HLA-DR & Antigen presentation, activation marker & $2.1(0.2)$ & $\{1(0)\}$ & $1.9(0.1)$ & $\{1(0)\}$ & $<0.05$ \\
\hline
\end{tabular}



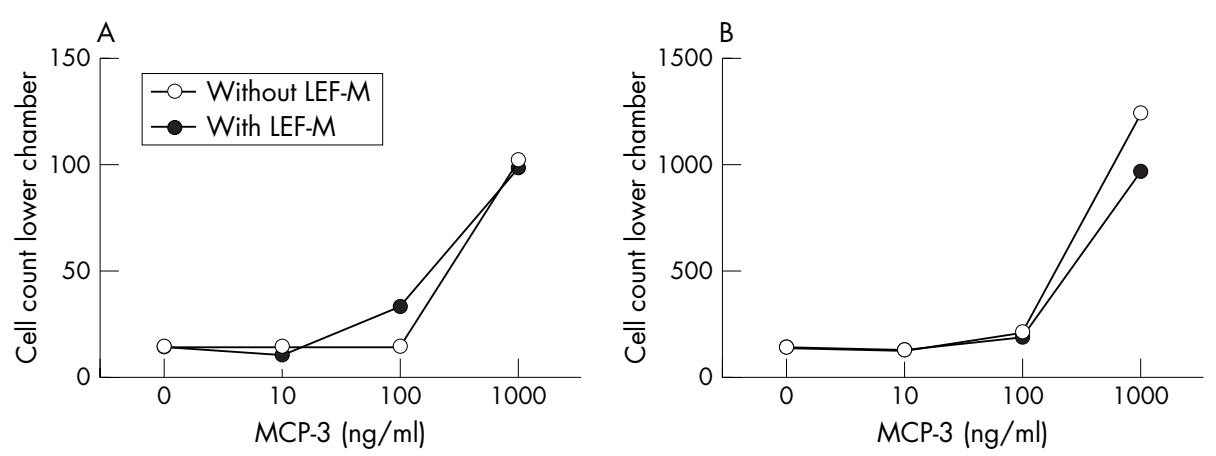

Figure 7 Leflunomide does not influence the chemotaxis of PBMC or monocytes. When chemotaxis induced by increasing concentrations of MCP-3 was assayed for PBMC (A) or monocytes (B), no difference could be seen between untreated cells or cells pretreated with $100 \mu M$ LEF-M.

incubation with LEF-M, the percentage of migrated CDI4 positive cells (that is, monocytes) was significantly decreased by $15(4) \%(p=0.006)$ compared with migration in the absence of LEF-M, while B and T cell subsets were similarly distributed among the migrated populations preincubated with or without LEF-M (fig 5).

This observation was further supported by data obtained in analyses of adhesion experiments: In these experiments the percentage of PBMC adherent to an EC monolayer decreased from 51 (8)\% without LEF-M to 40 (6)\% after pretreatment with LEF-M $(\mathrm{p}<0.05)$. When analysing the subsets, CD14 positive cells among the adherent PBMC decreased from 9 (2)\% without, to 5 ( 1 \% w with, LEF-M treatment $(\mathrm{p}<0.05)$. These data were confirmed by using highly purified monocytes whose potential to transmigrate was significantly inhibited by increasing dosages of LEF-M to a maximal degree of $55 \%$ at a concentration of $100 \mu \mathrm{mol} / \mathrm{l}$, results similar to those obtained by staining for CD14+ cells among transmigrated PBMC (fig 6).

Many ligands and receptors are known to have important roles in the different steps of extravasation (adhesion, rolling, binding, shearing) (tables 1 and 2). Several adhesion molecules on PBMC tended to decrease with LEF-M pretreatment, but most of these differences were not significant. However, CD44 expression on PBMC, and CD102 and HLA-DR expression on EC decreased significantly (tables 1 and 2).

\section{Effects on adhesion and hyaluronan binding}

As we observed a mild but significant decrease in the expression of CD44 after incubation with LEF-M (MFI 351 (15) without LEF-M $v 325$ (18) with LEF-M, p<0.05; table 1), further experiments were performed, which showed that this alteration in CD44 expression was limited to monocytes (MFI of CD44 on CD14 positive cells 949 (66) without $v 885$ (66) with LEF-M, $\mathrm{p}<0.005$ ). This decrease was paralleled also by a significant decrease in receptor functions-namely, binding of hyaluronic acid (MFI 23 (6) without LEF-M $v 17$ (4) with LEF-M, p <0.05), as observed in hyaluronan binding experiments. Thus, the reduction in CD44 expression had a functional equivalent in reduced hyaluronan binding.

\section{Chemotaxis is not significantly influenced by LEF-M}

We also investigated the potential influence of LEF-M on the chemotaxis of both PBMC and monocytes. To this end, increasing doses of MCP-3 (fig 7) or a combination of MCP-1 and MIP-l $\alpha$ (not shown) were used. Neither PBMC nor purified monocytes were affected in their chemotactic behaviour by LEF-M (fig 7). These data supported the notion that the altered migratory behaviour, of PBMC in general and of monocytes in particular, was not due to effects on chemotaxis but rather to other mechanisms such as the changes in adhesion described above.

\section{DISCUSSION}

The data obtained show a novel mode of action of leflunomide-namely, interference with TEM. This effect is seen when PBMC, whether derived from healthy subjects or RA donors, are preincubated with LEF-M. LEF-M also affects EC, although to a slightly smaller degree. However, the effect is particularly prominent when both EC and PBMC are exposed to LEF-M, as is the case in vivo. Under such circumstances PBMC migration is reduced by nearly $50 \%$. Others have found similar effects on isolated neutrophil cell populations. ${ }^{17}$ MTX did not affect TEM, indicating differences in the cellular effects of the two drugs, which might help to explain the benefit of the combination of both drugs in patients with RA. ${ }^{18}$

The accumulation of lymphocytes and monocytes/macrophages in the synovial membrane is a pivotal event in RA, because these cells fuel the inflammatory process and secrete various cytokines. Among PBMC, the relative effects of LEF-M on migration are particularly pronounced on monocytes. These cells are of major pathogenic importance because of their large accumulation in the RA synovial membrane, their secretion of proinflammatory cytokines, ${ }^{19}$ and because they are precursor cells for osteoclast differentiation. ${ }^{20}$ These effects of LEF-M were confirmed when purified monocyte populations were used. Thus, the overall reduction in cell migration and the additional particular effects on the proportion of migrating monocytes/macrophages help to explain the clinical efficacy of leflunomide on joint inflammation and destruction. ${ }^{6721}$ Studies of synovial biopsies have recently shown a decrease in synovial cellularity in patients treated with leflunomide. ${ }^{11}$ The concentration of LEF-M used in this study was the optimal inhibitory dose and within the therapeutic range. ${ }^{22}$

The effects observed seem to be mediated by the primary mode of action of LEF-M-namely, inhibition of DHODH, because uridine, which counteracts the DHODH mediated reduction in de novo pyrimidine synthesis, ${ }^{16}$ rescues cells from the inhibitory activity of LEF-M. Because there is evidence that DHODH inhibition changes the composition of the cell membrane, ${ }^{23}$ LEF-M may also alter cell membrane plasticity in addition to cell surface molecule expression. Thus, conceivably, the reduction in CD44 expression on monocytes has an important role. Because CD44 is ultimately involved in TEM, ${ }^{24-26}$ a decrease of its expression may have major effects on cell accumulation at inflammatory sites. Moreover, the down regulation of CD44 is also accompanied by decreased hyaluronan binding of PBMC, indicating that the LEF-M associated alteration of CD44 expression is associated with functional changes. This is supported by 
observations in experimental arthritis, where administration of anti-CD44 antibodies reduces arthritic activity. ${ }^{27-29}$ In addition, CD102 (intercellular adhesion molecule-2 (ICAM2)), an adhesion molecule that has an important role in transmigration and costimulatory signalling, ${ }^{30}$ was down regulated on EC. In accordance with the data presented, LEF-M also appears to affect cell adhesion..$^{31}{ }^{32}$ Each of these mechanisms alone may be of limited influence; however, taken together these actions appear to exert a significant overall effect, which is manifested in a significant reduction in transendothelial migration and, consequently, in antiinflammatory action. Some of the effects of LEF-M in these events may be due to its inhibitory activity on the glycosylation of adhesion molecules. ${ }^{33}$ Likewise, NF- $\kappa \mathrm{B}, \mathrm{a}$ transcription factor induced by proinflammatory cytokines, which is involved in adhesion molecule expression, ${ }^{34}$ is also inhibited by LEF-M. ${ }^{10}{ }^{35}$ Importantly, however, chemotaxis, another important event that triggers TEM, was not affected by LEF-M.

In conclusion, LEF-M inhibits TEM of inflammatory cells in a DHODH dependent manner, at least in part by reducing adhesion and transmigratory capacity owing to its effects on adhesion molecules. In conjunction with its inhibitory activity on proliferation, tumour necrosis factor production, and NF- $\kappa \mathrm{B}$, these findings add yet another dimension to the molecular and cellular basis underlying the clinical effects of this DMARD.

\section{ACKNOWLEDGEMENT}

We thank Aventis for kindly providing us with LEF-M.

\section{Authors' affiliations}

J Grisar, M Aringer, M D Köller, G H Stummvoll, D Eselböck, B Zwölfer, C W Steiner, J S Smolen, Division of Rheumatology, Department of Internal Medicine III, Medical University of Vienna, Vienna, Austria B Zierhut, L Wagner, Division of Endocrinology, Department of Internal Medicine III, Medical University of Vienna, Vienna, Austria

P Pietschmann, Department of Pathophysiology, Medical University of Vienna, Vienna, Austria

\section{REFERENCES}

1 Goronzy JJ, Weyand CM. Rheumatoid arthritis-epidemiology, pathology and pathogenesis. In: Klippel JH, Crofford U, Stone JH, Weyand CM, eds. Primer of the rheumatic diseases. Atlanta: Georgia Arthritis Foundation, 2001:209-18.

2 Choy EH, Panayi GS. Cytokine pathways and joint inflammation in rheumatoid arthritis. N Engl J Med 2001;344:907-16.

3 Bell AL, Magill MK, McKane R, Irvine AE. Human blood and synovial fluid neutrophils cultured in vitro undergo programmed cell death which is promoted by the addition of synovial fluid. Ann Rheum Dis 1995;54:910-15.

4 Kavanaugh AF, Davis LS, Jain RI, Nichols LA, Norris SH, Lipsky PE. A phase I/ II open label study of the safety and efficacy of an anti-ICAM-1 (intercellular adhesion molecule-1; CD54) monoclonal antibody in early rheumatoid arthritis. J Rheumatol 1996;23:1338-44.

5 Pietschmann P, Cush JJ, Lipsky PE, Oppenheimer-Marks N. Identification of subsets of human T cells capable of enhanced transendothelial migration. $J$ Immunol 1992;149:1 170-8.

6 Smolen JS, Kalden JR, Scott DL, Rozman B, Kvien TK, Larsen A, et al. Efficacy and safety of leflunomide compared with placebo and sulphasalazine in active rheumatoid arthritis: a double-blind, randomised, multicentre trial. European Leflunomide Study Group. Lancet 1999;353:259-66.

7 Emery P, Breedveld FC, Lemmel EM, Kaltwasser JP, Dawes PT, Gomor B, et al. A comparison of the efficacy and safety of leflunomide and methotrexate for the treatment of rheumatoid arthritis. Rheumatology (Oxford) 2000;39:655-65.

8 Greene S, Watanabe K, Braatz-Trulson J, Lou L. Inhibition of dihydroorotate dehydrogenase by the immunosuppressive agent leflunomide. Biochem Pharmacol 1995;50:861-7.

9 Chong AS, Rezai K, Gebel HM, Finnegan A, Foster P, Xu X, et al. Effects of leflunomide and other immunosuppressive agents on T cell proliferation in vitro. Transplantation 1996;61:140-5.
10 Manna SK, Aggarwal BB. Immunosuppressive leflunomide metabolite (A77 1726) blocks TNF-dependent nuclear factor-kappa $B$ activation and gene expression. J Immunol 1999;162:2095-102.

11 Kraan MC, Reece RJ, Barg EC, Smeets TJ, Farnell J, Rosenburg R, et al. Modulation of inflammation and metalloproteinase expression in synovial tissue by leflunomide and methotrexate in patients with active rheumatoid arthritis. Findings in a prospective, randomized, double-blind, parallel-design clinical trial in thirty-nine patients at two centers. Arthritis Rheum 2000;43: 1820-30

12 Reece RJ, Kraan MC, Radjenovic A, Veale DJ, O'Connor PJ, Ridgway JP, et al. Comparative assessment of leflunomide and methotrexate for the treatment of rheumatoid arthritis, by dynamic enhanced magnetic resonance imaging. Arthritis Rheum 2002;46:366-72.

13 Grisar J, Hahn P, Brosch S, Peterlik M, Smolen JS, Pietschmann P. Phenotypic characteristics of human monocytes undergoing transendothelial migration. Arthritis Res $2001 ; 3: 127-32$

14 Genestier L, Paillot R, Fournel S, Ferraro C, Miossec P, Revillard JP. Immunosuppressive properties of methotrexate: apoptosis and clonal deletion of activated peripheral $t$ cells. J Clin Invest 1998;102:322-8.

15 Piemonti L, Monti $\mathrm{P}$, Allavena P, Sironi M, Soldini L, Leone BE, et al. Glucocorticoids affect human dendritic cell differentiation and maturation. $J$ Immunol 1999; 162:6473-81

16 Cherwinski HM, Byars N, Ballaron SJ, Nakano GM, Young JM, Ransom JT. Leflunomide interferes with pyrimidine nucleotide biosynthesis. Inflamm Res 1995;44:317-22

17 Kraan MC, de Koster BM, Elferink JG, Post WJ, Breedveld F, Tak PP. Inhibition of neutrophil migration soon after initiation of treatment with leflunomide or methotrexate in patients with rheumatoid arthritis. Arthritis Rheum 2000;43: 1488-95

18 Kremer JM, Genovese MC, Cannon GW, Caldwell JR, Cush JJ, Furst DE, et al. Concomitant leflunomide therapy in patients with active rheumatoid arthritis despite stable doses of methotrexate. A randomized, double blind placebocontrolled trial. Ann Intern Med 2002;137:726-33.

19 Firestein GS, Alvaro-Gracia JM, Maki R. Quantitative analysis of cytokine gene expression in rheumatoid arthritis. J Immunol 1990;144:3347-53.

20 Teitelbaum SL. Bone resorption by osteoclasts. Science 2000;289:1504-8.

21 Sharp JT, Strand V, Leung H, Hurley F, Loew-Friedrich I. Treatment with leflunomide slows radiographic progression of rheumatoid arthritis: results from three randomized controlled trials of leflunomide in patients with active rheumatoid arthritis. Leflunomide Rheumatoid Arthritis Investigators Group. Arthritis Rheum 2000;43:495-505

22 Koch MJ, Brennan DC. Leflunomide: is there a place for its use in transplantation? Curr Opin Organ Transplant 2003;8:317-22.

23 Bruneau JM, Yea CM, Spinella-Jaegle S, Fudali C, Woodward K, Robson PA, et al. Purification of human dihydro-orotate dehydrogenase and its inhibition by $A 77$ 1726, the active metabolite of leflunomide. Biochem $J$ 1998;336:299-303.

24 Brown KL, Maiti A, Johnson P. Role of sulfation in CD44-mediated hyaluronan binding induced by inflammatory mediators in human $\mathrm{CDI} 4(+)$ peripheral blood monocytes. J Immunol 2001;167:5367-74.

25 DeGrendele HC, Estess P, Siegelman MH. Requirement for CD44 in activated $T$ cell extravasation into an inflammatory site. Science 1997;278:672-5

26 Johnson P, Maiti A, Brown KL, Li R. A role for the cell adhesion molecule CD44 and sulfation in leukocyte-endothelial cell adhesion during an inflammatory response? Biochem Pharmacol 2000;59:455-65.

27 Mikecz K, Brennan FR, Kim JH, Glant TT. Anti-CD44 treatment abrogates tissue oedema and leukocyte infiltration in murine arthritis. Nat Med 1995; 1:558-63.

28 Nedvetzki S, Walmsley M, Alpert E, Williams RO, Feldmann M, Naor D. CD44 involvement in experimental collagen induced arthritis (CIA). $J$ Autoimmun 1999;13:39-47.

29 Mikecz K, Dennis K, Shi M, Kim JH. Modulation of hyaluronan receptor (CD44) function in vivo in a murine model of rheumatoid arthritis. Arthritis Rheum 1999;42:659-68.

30 Carpenito C, Pyszniak AM, Takei F. ICAM-2 provides a costimulatory signal for T cell stimulation by allogenic class II MHC. Scand J Immunol 1997:45:248-54.

31 Dimitrijevic $M$, Bartlett RR. Leflunomide, a novel immunomodulating drug, inhibits homotypic adhesion of peripheral blood and synovial fluid mononuclear cells in rheumatoid arthritis. Inflamm Res 1996;45:550-6.

32 Breedveld FC, Dayer JM. Leflunomide: mode of action in the treatment of rheumatoid arthritis. Ann Rheum Dis 2000;59:841-9.

33 Rückemann K, Fairbanks LD, Carrey EA, Hawrylowicz CM, Richards DF, Kirschbaum $B$, et al. Leflunomide inhibits pyrimidine de novo synthesis in mitogen-stimulated T-lymphocytes from healthy humans. J Biol Chem 1998;34:21682-91.

34 Roebuck KA, Finnegan A. Regulation of intercellular adhesion molecule- 1 (CD54) gene expression. J Leukoc Biol 1999:66:876-88.

35 Manna SK, Mukhopadhyay A, Aggarwal BB. Leflunomide suppresses TNFinduced cellular responses: effects on NF-kappa B, activator protein-1, c-Jun $\mathrm{N}$-terminal protein kinase, and apoptosis. J Immunol 2000;165:5962-9. 